\title{
A CASE STUDY OF THE APPLICATION OF HAND-HELD MOBILE LASER SCANNING IN THE PLANNING OF AN ITALIAN FOREST (ALPE DI CATENAIA, TUSCANY)
}

\author{
S. Sofia ${ }^{1 *}$, S. Sferlazza $^{1}$, A. Mariottini ${ }^{2}$, M. Niccolini ${ }^{2}$, T. Coppi ${ }^{2}$, M. Miozzo ${ }^{2}$, T. La Mantia ${ }^{1}$, F. Maetzke ${ }^{1}$ \\ ${ }^{1}$ Department of Agriculture, Food and Forest Sciences, University of Palermo, Palermo, Italy \\ (serena.sofia, sebastiano.sferlazza,tommaso.lamantia, federico.maetzke)@unipa.it \\ ${ }^{2}$ D.R.E.Am. Italia, Pratovecchio, Arezzo, Italy \\ (niccolini,coppi,miozzo)@dream-italia.it; mariottinialessandra@gmail.com
}

\section{Commission 2 / Wg10}

KEY WORDS: Forest Planning, Hand-Held Mobile Laser Scanning, Point Cloud processing, Dendro-Auxometric Data, Simultaneous Localization and Mapping.

\begin{abstract}
:
Precision forestry is becoming a key sector for forest planning because it allows complex analyses of forest data to be carried out simply and economically. It contributes to the integration between technicians and operators in the sector by guaranteeing the transparency of the forest management operations (Corona et al., 2017). In the context of the progressive development of technology, we investigated the feasibility of using the hand-held mobile laser scanner (HMLS) system in different types of forest sites and comparison of the characteristics of individual trees (tree height, diameters at breast height) with traditional surveys, applied with the aim to validate the performance of the system for a future alternative methodology for forest planning thanks to the collaboration with the forestry company "Dimensione Ricerca Ecologia Ambiente Italia" (D.R.E.Am. Italia). GEOSLAM ZEB HORIZON TM laser scanner is a hand-held mobile laser scanner containing SLAM technology that can be solved the problem of no GNSS ${ }^{1}$ signal or poor signal under the forest canopy making it more practical for forest investigations (Gollob et al., 2020). 15 forest sample plots are selected to reflect different stand conditions in Mediterranean forests taking into count the development stage and density of the sub-canopy vegetation, as well as the species composition in the forest stands. The aim of this study is to show the possible extrinsic circumstances that make the method fail by varying the ecological status of forest plots.
\end{abstract}

\section{INTRODUCTION}

In the Italian territory, the sustainable management of forest resources combines the principles of conservation of the dynamic entity of ecosystems with the practical and economic feasibility of the survey for forestry companies. Planning is the indispensable tool for managing these problems and guaranteeing the sustainability of the man-environment relationship over time. Precision forestry is becoming a key sector for forest planning because it allows complex analyses of forest data to be carried out simply and economically and at the same time it favors the integration between technicians, operators in the sector, and local groups with a common interest in this issue (public bodies, local environmental associations, private forest owners). The transparency of the forest management operations is guaranteed during these operations (Corona et al., 2017). In the European and international context, Beland et al. (2019) observed how the laser scanning platforms made up a real revolution in surveys of last years bringing productivity and good economic savings for big companies. They show that the laser scanning platforms offer two main advantages in forest applications: 1to provide valuable information not accessible from a traditional survey in the field (e.g., stem maps, stem density, taper, and basal area, vertical profiles of $\mathrm{LAI}^{2}$, canopy roughness and cover fraction); 2- to acquire data quickly and with good accuracy of the laser pulse returns.

However, recent papers show the high costs of these laser scanning platforms and the restricted accessibility to the technical scientific documentation. An interdisciplinary

\footnotetext{
* Corresponding author

${ }^{1}$ GNSS= Global Navigation Satellite Systems

${ }^{2}$ LAI $=$ Leaf Area Index
}

collaboration is needed with the aim to combine the requests of private companies and scientific research and to define new standard data acquisition protocols suitable for any survey environment (Beland et al., 2019). About the actual state-ofthe-art laser instrumentation, Shao et al. (2020) demonstrate the good reliability of dendro-auxometric data from innovative technologies of ground-based laser scanning platforms (static terrestrial laser scanning and mobile laser scanning). This paper especially examines the efficiency in terms of survey productivity obtaining realistic results in a very short time. The described technologies have been tested through the development of a series of projects, to verify the possibilities of use in different areas of design, inventory, and planning. Our challenge is to transfer this wealth of knowledge and possibilities to the operational level, to research and professional work, identifying precise limits of application in forest planning operations.

In this work we studied the feasibility of using a portable laser scanner system (HMLS) with SLAM technology in different types of forest sites and comparing the characteristics of individual trees (tree height, crown diameters) with traditional surveys, applied to validate their performance as alternative survey. The forest sample plots are selected to represent different stand conditions in Mediterranean forests considering the stage, stem density, and density of the sub canopy vegetation, as well as the species composition in the forest stands. The aim of this study is to verify limits and difficulties of the method in relation to the different ecological characteristics of the investigated forests. 


\section{MATERIALS AND METHODS}

\subsection{Experimental set-up}

The research was organized in the following steps: 1-Identification of sampling areas for each forest stand according to different ecological features and managements, 2-LIDAR ${ }^{3}$ data collection and traditional measurements in field,

3-LIDAR data pre-processing,

4-LIDAR data processing and extraction of tree characteristics,

5-Tree volume estimation.

\subsection{Study area}

The Alpe di Catenaia complex covers an area of 2,341.95 hectares distributed among the municipalities of Chiusi della Verna, Chitignano and Subbiano in Tuscany (Italy).

The complex is divided into three sections:

- "Monte Calvano-Monte Silvestre" (245,23.42 hectares),

- "Chiusi-Chitignano" (815,39.48 hectares),

- "Subbiano" (1,280.53.04 hectares).

The first section "Monte Silvestre" is located further north at an average altitude of vary from 1.050-1.100 m a.s.l. (the minimum altitude: $950 \mathrm{~m}$ a.s.l. to location "Compito", $\max$ altitude: $1.253 \mathrm{~m}$ a.s.1. to "Calvano"). The prevalent exposure is South-South/East, the morphology is very uneven with steep slopes and pseudo-calancholic formations, with numerous small streams in between embedded.

In the section "Chiusi-Chitignano", the morphology is sweet and regular, only locally furrowed by deep incisions fluvial of numerous perennial torrents. The prevailing exposure is West, the average altitudes in this section are around $1.000 \mathrm{~m}$ in the range between 490 and $1.265 \mathrm{~m}$ a.s.1..

The third section "Subbiano" is characterised by sweet and regular morphology with limited sloping areas. The prevalent exposure is West, the average altitudes is $1,000 \mathrm{~m}$ a.s.l. in the range between 450 and 1,420 $\mathrm{m}$ a.s.l. . Currently the property belongs to regional authority, as for the geological matrix, the ridge skeleton is a turbidite formation consisting of arenaceous deposits with facies flysch, with alternating psammitic and pelitic layers, locally called "Macigno". To the north emerges the formation called "Alberese": a powerful series consisting of an alternation of white and very compact marly limestones that alternate layers of white-yellowish or grey marl and clayey marl and thin sandstone layers.

For the local Apennine climate, the thermo-pluviometric stations of "Biforco", "La Verna", "Bibbiena" and "Subbiano" relevant to our study were considered, for the definition of rainfall and climate in the sampling area.

The average annual rainfall of the "La Verna" station is 1224.6 $\mathrm{mm}$. The monthly distribution of rainfall shows an autumn maximum in the month of November $(165.1 \mathrm{~mm})$ and a summer minimum in the month of July and a summer minimum in July (48.9 mm). Rainfall remains relatively high in the months of January to May (about $100 \mathrm{~mm}$ per month) and then decreases rapidly until the summer minimum. As for the temperatures, the average annual temperature is $9.2^{\circ} \mathrm{C}$, while the hottest month is July. The coldest month is January, followed by December and February. The average annual precipitation is $1016.0 \mathrm{~mm}$. The monthly distribution of precipitation shows an autumn maximum in October (165.1 $\mathrm{mm}$ ) and a summer minimum in July (28.0 mm).
The Alpe di Catenaia forest ecosystem is characterized by vegetation that can be distinguished in the following types: prairies, shrublands, Beech woods, Downy Oaks woods, Chestnut woods, Mixed Forests (Turkey Oak-Hop Hornbeam), Artificial stands of Conifer (Silver Fir and Black Pine), and rocky vegetation formations.

According to the classification in vegetation belts of Pignatti (1979) we can identify:

- the sub-Atlantic belt, in which we find beech forests, pastures, and shrublands;

- mid-European or sub-Mediterranean belt, in which there are turkey oak, chestnut, oak, shrub, meadows, and other forms of anthropic alteration.

The forest populations occupy the territory from the lower limits of the property to the ridge, mixed in a pattern of pastures and shrubs (Cytisus scoparius).

The beech forests (Fagus sylvatica), generally monospecific, are distributed from the lower altitudes up to the ridge. There are also other species than beech (Castanea sativa, Quercus cerris, Abies alba, Prunus avium) at the dominant plane but their number is low.

The chestnut woods (Castanea sativa) are managed as fruit woods, mature coppices and transitional forests. They occupy generally gentle morphologies, with limited stonyness and absence of rockiness (significant acidification), and are subject to limited water stress in summer. In the upper level chestnut woods, Turkey oak (Quercus cerris), European plane tree (Ostrya carpinifolia), beech (Fagus sylvatica), downy oak (Quercus pubescens), sweet cherry (Prunus avium), sycamore maple (Acer pseudoplatanus) are sometimes mixed.

Mixed forests (Turkey Oak-Hop Hornbeam) are characterized by the mixture, in the upper floor, of Turkey oak (Quercus cerris), European hophornbeam (Ostrya carpinifolia), and locally Chestnut woods (Castanea sativa). The prevailing species is the turkey oak, locally replaced by the hophornbeam in northern exposures with high slopes. It develops on poorly evolved soils and strongly disturbed (eroded and leached soil of nutrients) and it is subject to summer water stress. The main species are locally accompanied by Bosnian Maple (Acer opalus subsp. obtusatum), Flowering ash (Fraxinus ornus), and Turkey oak (Quercus cerris).

Oaks are present at the lowest altitudes of the forest complex. They are characteristic of little evolved acid soils, subject to strong drying in summer when temperatures can be high. In the upper level Downy oak (Quercus pubescens) dominates with Turkey oak (Quercus cerris) and Whitebeam (Sorbus aria).

Artificial stands are composed of Silver Fir (Abies alba), Douglas fir (Pseudotsuga menziesii) and Black Pine (Pinus nigra) high forests.

Silver Fir (Abies alba) is naturally widespread in beech forests and, to a lesser extent, also in turkey oak forests. Mature stands are capable of abundant and vital regeneration, such as to ensure the development of new fir stands.

The Douglas fir forests (Pseudotsuga menziesii) derive from relatively recent reforestations on former farmland, distributed in strips on less deep soils; they have high unevenness in development and vegetative vigour.

The Black Pine (Pinus nigra) stands on Mount "Calvano" were planted for protection purposes on extremely thin soils coming from calcareous rocks (Pignatti S. 1979, Blasi C. 2010, Mondino GP. And Bernetti G., 1998).

\footnotetext{
${ }^{3}$ LIDAR=Laser Imaging Detection and Ranging
} 


\section{3}

\section{Field data}

The forest surveys carried out, both with traditional measurements and with the use of the HMLS, are aimed at collecting data on the various stands to estimate the existing wood mass.

The sample areas were chosen according to the type as follows:

- Mixed broadleaf forests,

- Conifers forests,

- Broadleaf forests,

- Chestnut forests,

- Coppices at cut.

15 circular sampling plots have been identified for each stand layer with a high productive vocation and differ for forest type class (broadleaved, conifers, and mixed), dominant species, forest structure (one- or two-layered), regeneration and stand class (see Table 1 and Figure 1 from 1.a to 1.e). To optimize sampling efficiency, the test plots are distributed according to the unaligned systematic sampling scheme. This scheme involves the random extraction of a sampling plots position within a Forest complex and results in better balanced estimates, with a higher degree of accuracy than simple random sampling.

Circular plots with a radius ranging from 10 to $25 \mathrm{~m}$ accordingly with the average height of each stand were positioned and their center was georeferenced by GPS positioning.

\subsection{HMLS platform and Data collection}

GEOSLAM ZEB HORIZON TM (GEOSLAM ltd. (UK) laser scanner is a lightweight hand-held mobile laser scanner (weight: $3.5 \mathrm{~kg}$ ) containing an eye-safe laser that provides 300,000 measurements per second with a maximum laser beam of $100 \mathrm{~m}$. Really practical for outside investigation, this HLMS uses Simultaneous Localization and Mapping (SLAM) technology developed by the robotics and machine vision community (see Figure 2a). In this way, the problem of no GNSS signal or poor signal under the forest canopy can be solved using this technique. Moreover, the data acquisition with GEOSLAM ZEB HORIZON TM starts with IMU initialization to establish the local coordinate reference system. The VLP-16 $6^{4}(0.83 \mathrm{~kg})(0.83 \mathrm{~kg})$ has 16 channels and uses time-of-flight Light Detection and Ranging (LIDAR) technology to measure the distance with a continuous wavelength of $903 \mathrm{~nm}$ and range accuracy of $\pm 3 \mathrm{~cm}$. The field of view of the VLP-16 is $360 \circ \times 30^{\circ}$ with a horizontal angular resolution of $0.1^{\circ-}-0.4^{\circ}$ and a vertical angular resolution of $2^{\circ}$. The combination of the internal and external rotation of VLP16 attached to the GEOSLAM ZEB HORIZON TM results in an angular field of view of $360^{\circ} \times 270^{\circ}$. The size of the collection point data is $100-200 \mathrm{MB}$ for a minute.

The scanner is easy to handle in forestry surveys thanks to the compact design $(100 \mathrm{~mm} \times 200 \mathrm{~mm} \times 240 \mathrm{~mm}$ for the handheld part) and the longevity of battery capacity ( 3.50 hours continued). Finally, it can be equipped with an optional Firefly 8 si camera with $4 \mathrm{k}$ resolution to record different videos of the sampling area, useful for forest quality aspect inspection (ZEB HORIZON тм -GeoSLAM, 2020; Gollob et al., 2020; Ryding et al., 2015; Liang et al., 2015).

At the end of March 2021, the traditional surveys and laser scannings with GeoSLAM GEOSLAM ZEB HORIZON TM) were performed in the same 20 areas identified in order to compare the results obtained.
The HMLS scanning starts with 15 seconds of initialization in the center of the sampling plots, in order to stabilize the laser scanning. Then the operator bearing HMLS starts walking within the sampling area following a star shaped trajectory, while the rotating scanner head captures 3D data. According to the tests with similar laser scanning technology (Gollob et al. 2020, Bauwens et al. 2016, Del Perugia et al. 2019, Liang et al. 2018) this sampling scheme gives the better acquisition of $3 \mathrm{~d}$ data of full environment and better results of elaboration from SLAM technology. The schemes used for the mobile surveys are presented in Figure $2 b$.

At the end of the survey (the time of scanning is 10-15 minutes for each sampling area), the operator returns to the start point and the scanning process ended.

\subsection{LIDAR Data Pre-processing}

Pre-processing of 3D data as follows 4 main steps:

1-Registration and conversion of collected 3D data into LAS format and input of GPS positions,

2-Statistical removal of high and low-level outliers,

3-Filtering of ground points,

4-Removing the impact of terrain on the elevation values of individual laser points.

After the forest surveys, in the first step, all the 3D data acquired from the laser scanning are processed with several automatic processing steps to be converted in LAS format using the GeoSLAM Hub 6.1 desktop software.

Then the GPS positions in txt format is linked to each 3D processed data through the software tool "Adjust to Control" specifying a non-rigid transformation adjustment for a better result. Parameter settings used in the software for export of LAS format are "100\% of points", "point color: time", "timestamp: None" and "Smooth accepted".

While transporting the LAS point clouds into LIDAR360 for subsequent processing steps, the data clouds were referred to a local geographic reference system (WGS84 ESPG:4326) and cropped into a circular section. In the latter report, the GPS center position values of the sampling plot and the radius values were chosen and annotated in the field in order to reduce processing time. LIDAR360 software was used for preprocessing steps 2-3-4.

Thanks to the software's specific "remove outliers" tool, the statistical noise (low and high-level outliers) was removed. This algorithm searches for each point's neighbours within a definite area of the point cloud and it calculates the average distance between the point and its neighbouring points. Then, the mean and standard deviation of these distances are calculated for all points. If the average distance of a point from its neighbours is larger than the maximum distance (maximum distance $=$ mean $+\mathrm{n} *$ standard deviation, where $\mathrm{n}$ is userdefined multiple numbers), it is considered as an outlier and it is removed from the original point cloud. High-level error is usually caused by the returns of high-flying objects (such as birds) during the process of data collection; low-level gross errors are returns with extremely low attitudes caused by the multipath effect of a laser pulse. Other software tools such as "Filter Ground Points" (extraction ground points from TLS point cloud data) and "Normalize by Ground Points" (removing the effects of the topographic survey on the elevation value of the point cloud data) allow to have a perfect point cloud for extraction of dendrometric data without noise or instrument errors (GeoSLAM Hub 6.1 Development Team, 2021; LIDAR360 Development Team, 2020; Chen et al., 2019).

\footnotetext{
${ }^{4}$ VLP $=$ Velodyne's Puck Lidar sensor TM
} 


\subsection{Extraction of single-tree attributes from the Point Clouds}

The Point cloud processing procedure is divided into the following steps:

1- Identification of cylindrical elements in point cloud through Batch Extraction of DBH;

2- Point Cloud Segmentation from cylindrical elements identified:

3-Extraction of Individual other dendrometric values

(tree positions and height).

It is important to give attention to the results of the identification of cylindrical elements from the LIDAR360 software. The algorithm aggregates several statistics such as fitting certainty of the tree trunk and DBH circle to categorize fitting confidence into three levels: Low, Medium, High. The min-max height range is greater than $0.4 \mathrm{~m}$ when fitting DBH in batch extraction mode singular cylindrical elements with a low confidence level can be detected and removed. An image of Point cloud processing from the graphical user interface of LIDAR360 is presented in Figure 3.

In the second and third step, the point cloud segmentation method developed by Tao et al. (2015) for TLS data using a bottom-up approach to identify individual trees was applied. This type of method is worth for the HMLS data because often the TLS data, such as the HMLS data, is acquired below the canopy where tree stems can be readily observed and delineate the spatial extent of individual trees within a forest or stand. The result of point cloud processing is a spreadsheet-based format with the total information of every stem present in sample plots (LIDAR360 Development Team, 2020, Tao et al., 2015).

\subsection{Traditional survey}

We carried out a traditional survey in each plot to detect the single-tree attributes ( $\mathrm{DBH}$ and $\mathrm{H})$ : diameter at breast height $(\mathrm{DBH})$ greater than $9.5 \mathrm{~cm}(\mathrm{DBH} 1.30>=9.5)$ and height $(\mathrm{H})$ of trees were measured, using traditional instruments such as the caliper and hypsometer Haglöf Vertex IV. A traditional survey required about 1 -work hour for each plot. The singletree attributes measured from the traditional survey were assumed as error free here and used as reference data to evaluate the estimates produced from HMLS scans.

\subsection{Data processing and analysis}

To assess the accuracy of DBH and $\mathrm{H}$, we calculated the coefficient of determination $\left(\mathrm{R}^{2}\right)$, the root mean square error (RMSE) and bias as follows:

$$
\begin{aligned}
& R M S E=\sqrt{\frac{\sum_{i=1}^{n}\left(X_{\mathrm{TS}}-X_{\mathrm{IS}}\right)^{2}}{n}} \\
& \text { bias }=\frac{\sum_{i=1}^{n}\left(X_{\mathrm{TS}}-X_{\mathrm{IS}}\right)}{n}
\end{aligned}
$$

where $\quad n=$ the number of trees resulting from the traditional survey (TS)

$X_{\mathrm{TS}}=$ the value of the tree attribute measured in TS

$X_{\mathrm{IS}}=$ the estimated value of the attribute for each $i$-th tree from HMLS scan

Using measured DBH and $\mathrm{H}$ by traditional survey (TS) and estimated ones by HMLS scans (innovative survey, IS), the following parameters were calculated for each plot: number of trees $(\mathrm{N})$; basal area $\left(\mathrm{G}\right.$ in $\left.\mathrm{m}^{2}\right)$; volume $\left(\mathrm{V}\right.$ in $\left.\mathrm{m}^{3}\right)$ according to mathematical models developed by Tabacchi et al. (2011). Number of trees $(\mathrm{N})$, basal area $(\mathrm{G})$ and volume $(\mathrm{V})$ computed by TS are compared with those resulting from IS. Before data analysis, we checked normality assumption of N, V and G per each survey method performing two normality tests, Pearson chi-square and Shapiro-Francia. Two-samples t-test was used to compare the means of $\mathrm{N}, \mathrm{V}$ and $\mathrm{G}$ for each survey method. Homogeneity of variances were first checked using F-test. The analyses were carried out using the software program $\mathrm{R}$, version 4.0.5. (R Development Core Team, 2021). For all statistical analyses, the significance level was at $p<0.05$.

\section{RESULTS AND DISCUSSION}

We compared the characteristics of the individual trees measured by the laser scan data processing to the values measured in the field. Our tests show a high variability of the results in the different sampling areas and a general tendency to obtain higher values of each variable with the HMLS method compared to the values calculated with the traditional method. Table 2 reports the accuracy of individual tree attributes (DBH and $\mathrm{H}$ ) computed by traditional survey and HMLS scans. With regards to DBH, the coefficient of determination across all plots was higher than 0.96 revealing a good fit between the HMLS scans and the reference data. The RMSE was 3.52 and the bias was 2.40 . Our results are slightly higher to those reported by Giannetti et al. 2018, Maas et al. 2008, Oveland et al. 2018. For H, the RMSE and bias were 4.02 and 0.19 respectively. The tree height assessment provided better results in conifers stands. In the case of broadleaved forest stands with presence of dense vegetation layers and multi-layered structure, RMSE and bias values were higher than the ones obtained for conifers stands. Regarding the results of conifers forest plots, the DBH assessment provided good results compared to field data. For example, The RMSE of plot n. 6 (Silver Fir) was $2.913 \mathrm{~cm}(\mathrm{DBH})$ and $2.175 \mathrm{~m}(\mathrm{~T})$ and the bias was $2.4127 \mathrm{~cm}(\mathrm{DBH})$ and $0.3875 \mathrm{~m}$ (T) for scans data and field data, respectively (see figure n.4.ab). This good match from the results of conifers forest plots sampling areas is caused to the linear and simple structure of this forest ecosystem. When observing the broadleaved forest plot's results, many cases of difference between the scans data and field data were observed. In the Beech cases, the RMSE of all plots of Beech was $3.284 \mathrm{~cm}(\mathrm{DBH})$ and $4.07157 \mathrm{~m}(\mathrm{H})$ and the bias was $1.8404 \mathrm{~cm}(\mathrm{DBH})$ and $0.4727 \mathrm{~m}(\mathrm{H})$ for scans data and field data, respectively (see figure n.4.c-d). These results are similar to the conifers forest plots due to your linear and simple structure of trees. Regarding the Turkey Oak plots, RMSE of all plots was $3.151 \mathrm{~cm}(\mathrm{DBH})$ and $5.574 \mathrm{~m}(\mathrm{H})$ and the bias was $1.5992 \mathrm{~cm}(\mathrm{DBH})$ and $0.603 \mathrm{~m}(\mathrm{H})$ for scans data and field data, respectively. These results show that the singular structure of species influences the condition of laser scanning and extraction of good dendrometric values. The irregular structure of stem and more side branches of different trees compromise the extraction of dendrometric values through the automatic algorithms. Another obstacle met during the extraction of $\mathrm{DBH}$ is related to the complexity of ecosystems featured by multiple layers in the forest structure and a significant presence of shrub vegetation under the canopy of dominant tree species. A general analysis of data showed no significant effect due to survey method on the computed dendrometric parameters per plot $(N, G$ and $V)$ (Figure 5-7). 


\section{CONCLUSION AND FUTURE WORK}

This work shows that the results of laser scanning change according to the forest ecosystems present in sample plots. Such a variability of the environmental condition in the Mediterranean forest types, dominated by conifers and evergreen broadleaves, influenced the time spent on the segmentation and single-tree attribute extraction in order to have good results of laser scanning. However, data collection with HMLS is significantly faster than traditional data collection (15 minutes of innovative forest survey versus 4560 minutes of traditional forest survey for a single area) contributing to save time and money during data collection with innovative methods that comply with forest planning standards. By the way, in literature there are only a few case studies of forest laser system sampling focused on the Italian forest context. We plan to test different sampling approaches regarding various spatial and vegetation variables type (diversified by slope, elevation, soil surface types, forest structure, government shape, single tree structure, and more...) under and over the canopy, with the same set of instruments and multiple repetitions. Such work, under the way, is intended to identify also the better procedures of point cloud segmentation for every Mediterranean forest type, by testing other algorithms as in the bibliography. Such a planned approach could be an interesting tool to help decision-making on forest management.

\begin{tabular}{|l|c|c|c|c|c|}
\hline \multicolumn{2}{|c|}{} & $\begin{array}{c}\text { Dominant } \\
\text { species }\end{array}$ & Slope & $\begin{array}{c}\text { Regenerati } \\
\text { on class }\end{array}$ & $\begin{array}{c}\text { Stand } \\
\text { class }\end{array}$ \\
\hline \multirow{2}{*}{$\begin{array}{c}\text { Forest } \\
\text { types } \\
\text { classes }\end{array}$} & \multirow{3}{*}{ conifers } & Slack Pine & $5-15 \%$ & 1 & 2 \\
\cline { 3 - 6 } & & Silver Fir & $15-30 \%$ & 0 & 3 \\
\cline { 3 - 6 } & bouglas fir & $15-30 \%$ & 0 & 1 \\
\cline { 3 - 6 } & $\begin{array}{c}\text { Turkey } \\
\text { Oak }\end{array}$ & $15-30 \%$ & 4 & 2 \\
\cline { 3 - 6 } & Beech & $30-50 \%$ & 1 & 2 \\
\hline
\end{tabular}

Forest type: conifers, broadleaved, mixed, mixed broadleaved species, mixed coniferus species.

Regeneration class: 0 - no regeneration; $1-<1.3 \mathrm{~m}$ coverage $<33 \%$; 2 $>1.3 \mathrm{~m}$ coverage $<33 \%$; $3->1.3 \mathrm{~m}$ coverage $33-66 \%$; $4->1.3 \mathrm{~m}$ coverage $>66 \%$.

Stand class: 1 , DBH $<22 \mathrm{~cm} ; 2,>50 \%$ DBH $22-37 \mathrm{~cm} ; 3,>50 \% 37-52$ $\mathrm{cm}$.

Table 1 Main characteristics of forest types classes investigated.

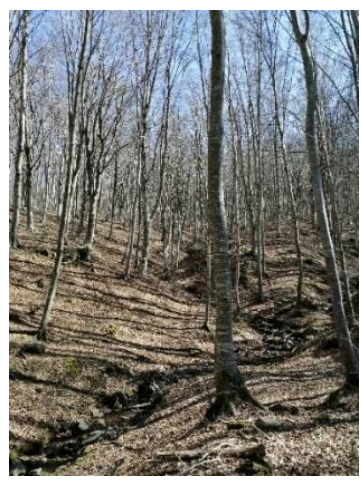

Figure 1.a Beech forest, plot 13).

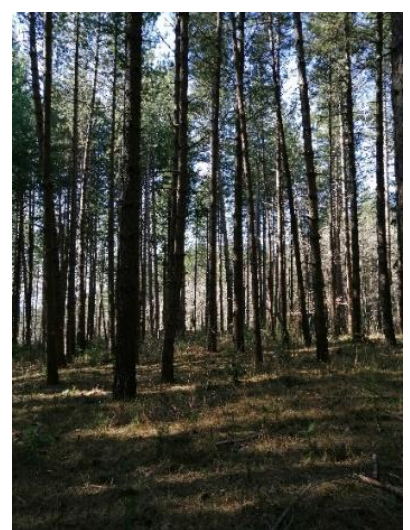

Figure 1.b Black Pine forest, plot 3

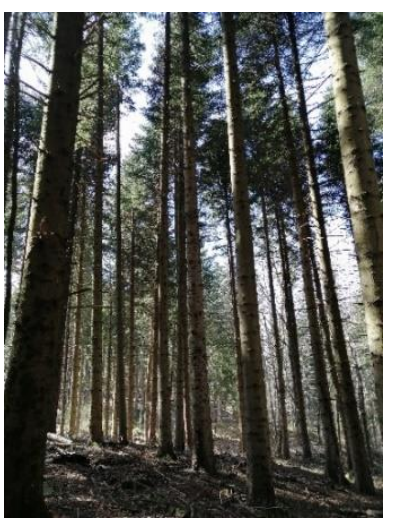

Figure 1.c Silver Fir, plot 4

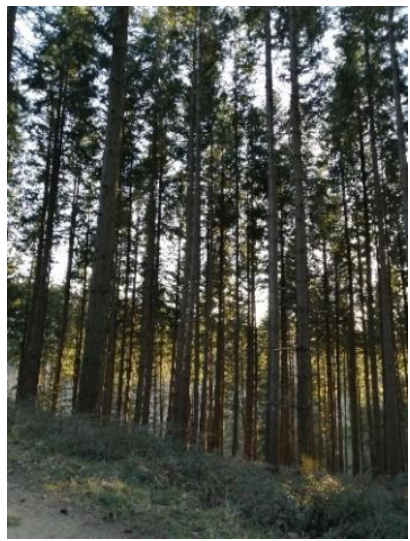

Figure 1.d Douglas fir forest, plot 8

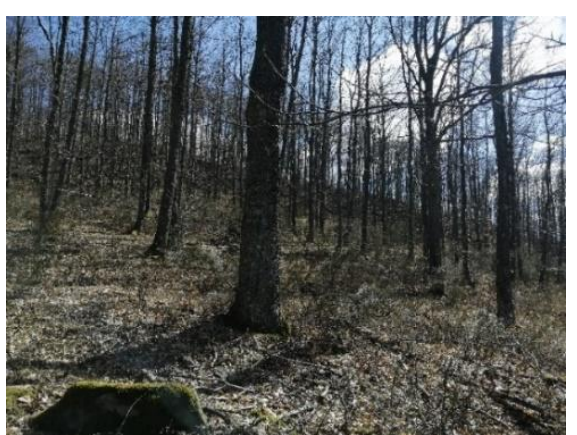

Figure 1.e Turkey Oak forest, plot 9 


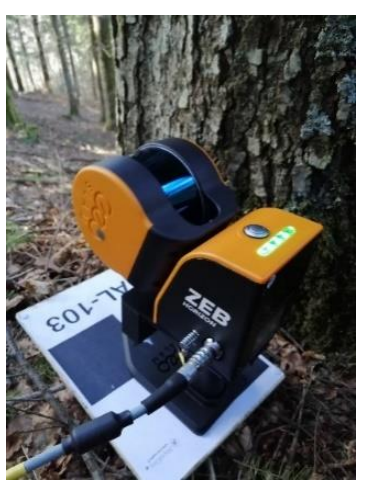

Figure 2.a GEOSLAM ZEB HORIZON TM laser scanner.

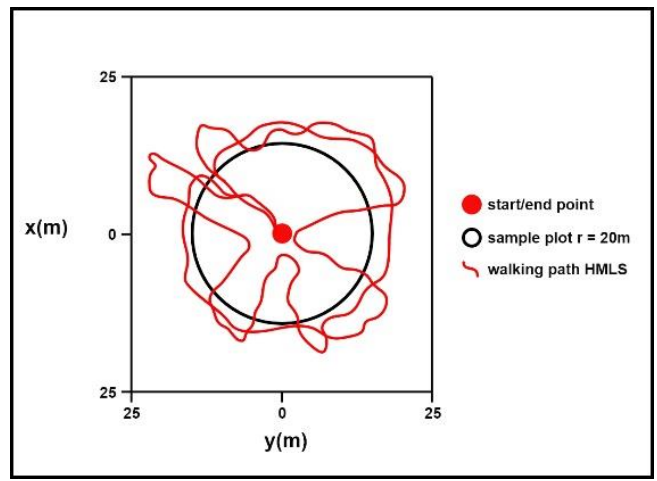

Figure 2.b The star scheme of walking path used for mobile laser scanning.

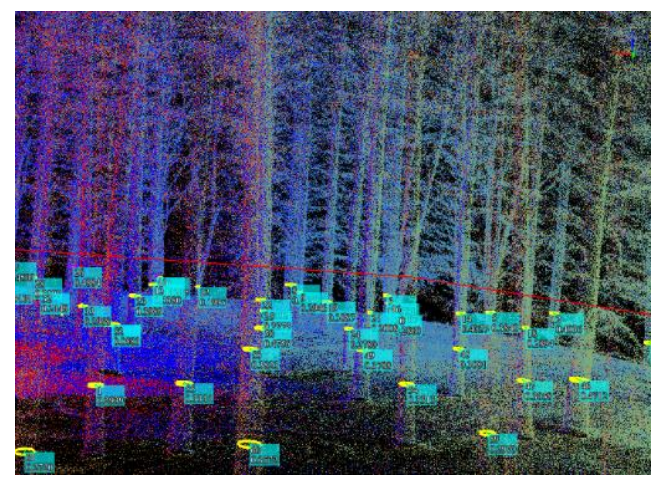

Figure 3 Images of point cloud processing from the graphical user interface of LIDAR360.

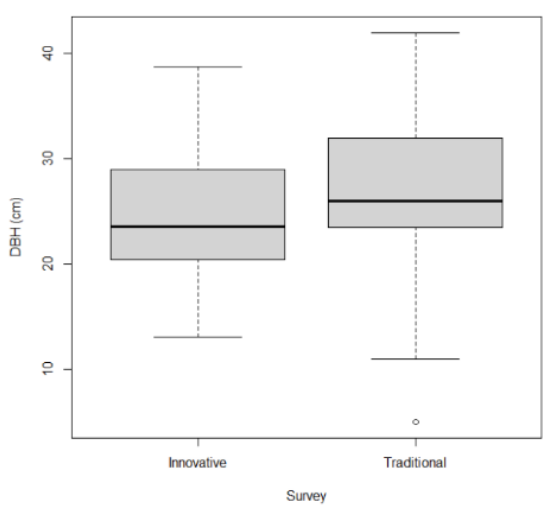

Figure 4.a Boxplots with resulting values for diameter at breast height (DBH) of plot 6-Silver Fir forest.

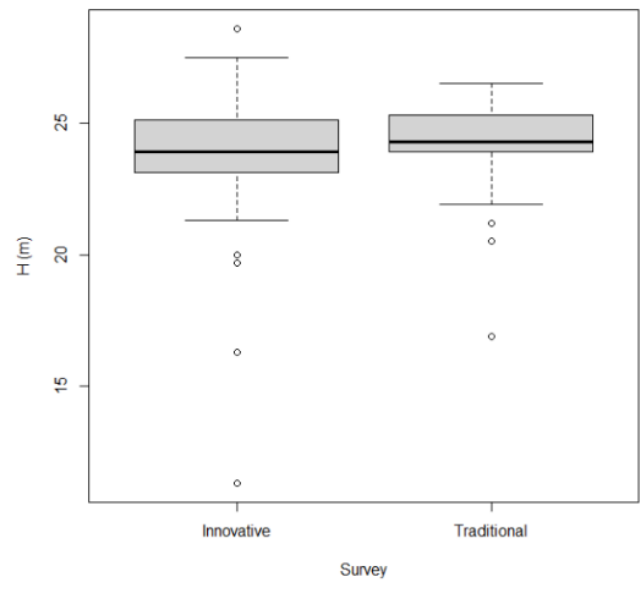

Figure 4.b Boxplots with resulting values for tree height $(\mathrm{H})$ of plot 6-Silver Fir forest.

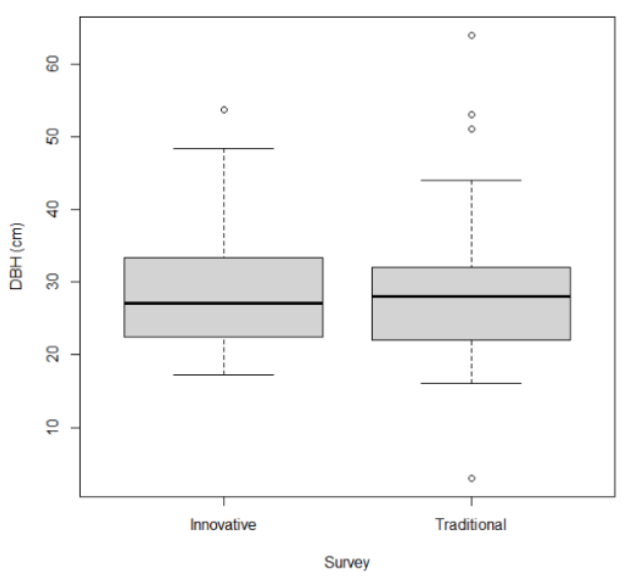

Figure 4.c Boxplots with resulting values for diameter at breast height $(\mathrm{DBH})$ of plot 13-Beech forest.

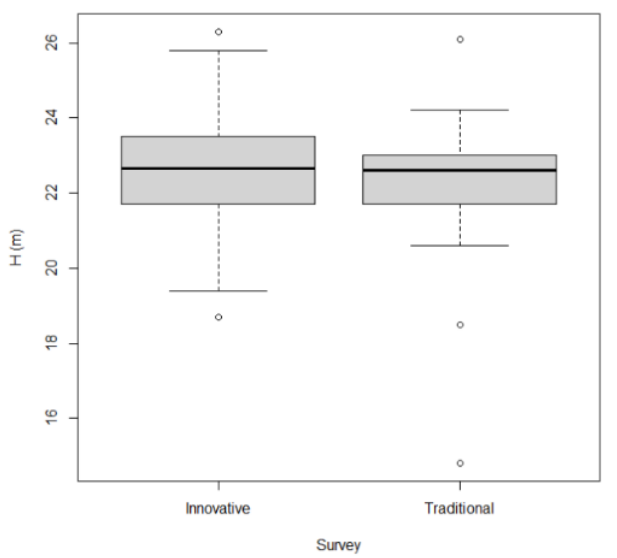

Figure 4.d Boxplots with resulting values for tree height $(\mathrm{H})$ of plot 13-Beech forest. 


\begin{tabular}{|c|c|c|c|c|c|}
\hline \multirow{2}{*}{ Plot ID } & \multicolumn{3}{|c|}{ DBH $(\mathrm{cm})$} & \multicolumn{2}{c|}{$\mathrm{H}(\mathrm{cm})$} \\
\cline { 2 - 6 } & $\mathrm{R}^{2}$ & RMSE & bias & RMSE & bias \\
\hline 1 & 0.984 & 4.623 & 4.356 & 5.240 & 3.578 \\
\hline 2 & 0.946 & 3.989 & 2.942 & 4.126 & 1.928 \\
\hline 3 & 0.949 & 4.022 & 3.309 & 5.851 & 2.520 \\
\hline 4 & 0.997 & 2.913 & 2.413 & 2.175 & 0.388 \\
\hline 5 & 0.977 & 4.789 & 4.259 & 2.493 & -1.650 \\
\hline 6 & 0.992 & 2.490 & -0.286 & 6.283 & 2.971 \\
\hline 7 & 0.952 & 4.189 & 2.852 & 4.384 & -0.358 \\
\hline 8 & 0.982 & 1.972 & 0.095 & 5.654 & -0.616 \\
\hline 9 & 0.947 & 2.860 & -1.172 & 2.114 & -0.292 \\
\hline 10 & 0.976 & 3.959 & 3.589 & 3.309 & 1.656 \\
\hline 11 & 0.898 & 3.524 & 2.465 & 4.297 & -1.012 \\
\hline 12 & 0.972 & 4.617 & 3.831 & 4.037 & -3.290 \\
\hline 13 & 0.975 & 3.392 & 3.163 & 4.425 & -2.884 \\
\hline 14 & 0.897 & 3.309 & 2.299 & 3.267 & -2.230 \\
\hline 15 & 0.977 & 2.154 & 1.896 & 2.737 & 2.178 \\
\hline All & 0.961 & 3.520 & 2.401 & 4.026 & 0.192 \\
\hline
\end{tabular}

DBH: diameter at breast height, $\mathrm{H}$ : height;

$\underline{R^{2}}$ : coefficient of determination, RMSE: root mean square error

RMSE and bias of DBH are reported in centimeter, RMSE and bias of height are reported in meters.

Table 2 Summary statistics of single-tree attributes (DBH and $\mathrm{H}$ ) computed by traditional survey and HMLS scans.

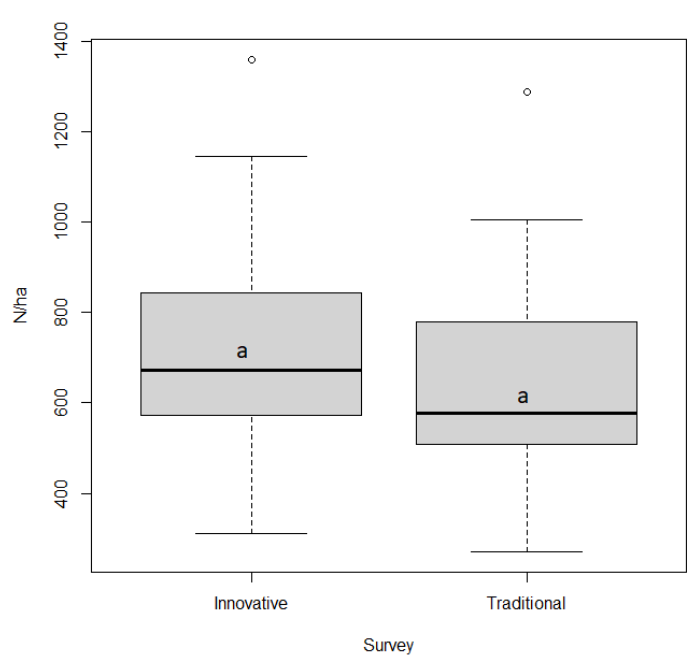

Figure 5 Boxplot of number of trees (N/ha) computed for each plot by traditional and innovative survey. Boxes with different letters indicate a statistically significant difference $(\mathrm{p}<0.05)$.

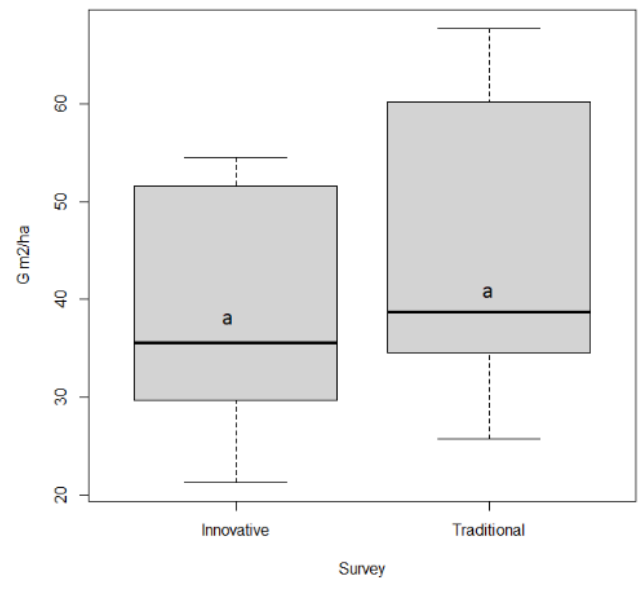

Figure 6 Boxplot of basal area $\left(\mathrm{G}, \mathrm{m}^{2} / \mathrm{ha}\right)$ computed for each plot by traditional and innovative survey. Boxes with different letters indicate a statistically significant difference $(\mathrm{p}<0.05)$.

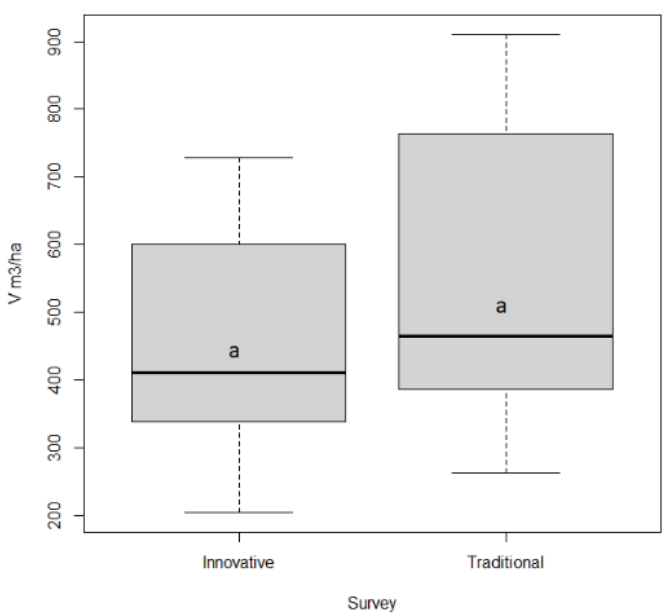

Figure 7 Boxplot of volume (V, $\mathrm{m}^{3} / \mathrm{ha}$ ) computed for each plot by traditional and innovative survey. Boxes with different letters indicate a statistically significant difference $(\mathrm{p}<0.05)$. 


\section{REFERENCES}

Bauwens, S., Bartholomeus, H., Calders, K., Lejeune, P., 2016. Forest Inventory with Terrestrial LiDAR: A Comparison of Static and Hand-Held Mobile Laser Scanning. Forests, 7, 127. doi.org/10.3390/f7060127

Beland M, Parkerb G., Sparrowc B., Hardingd D., Chasmere L., Phinnf S., Antonarakisg A., Strahlerh A., 2019. On promoting the use of lidar systems in forest ecosystem research. Forest Ecology and Management $450: 117484$. doi.org/10.1016/j.foreco.2019.117484

Blasi C., 2010. La vegetazione d'Italia con Carta delle Serie di Vegetazione in scala 1:500.000 Palombi e Partner S.r.L., Roma.

Chen, S., Liu, H., Feng, Z., Shen, C., Chen, P., 2019. Applicability of personal laser scanning in forestry inventory. PLoS ONE 14(2): e0211392.

doi.org/10.1371/journal.pone.0211392

Corona, P., Chianucci, F., Quatrini, V., Civitarese, V., Clementel, F., Costa, C., Floris, A., Menesatti, P., Puletti, N., Sperandio, G., Verani, S., Turco, R., Bernardini, V., Plutino, M., Scrinzi, G., 2017. Precision forestry: riferimenti concettuali, strumenti e prospettive di diffusione in Italia. Forest@ 14: 1-21. doi.org/10.3832/efor2285-014

GeoSLAM Hub 6.1 Development Team, 2021. Commercial software of GeoSlam company.

https://geoslam.com/solutions/geoslam-hub/

Giannetti, F., Puletti, N., Quatrini, V., Travaglini, D.,Bottalico, F., Corona, P., Chirici, G., 2018. Integrating terrestrial and airborne laser scanning for the assessment of single tree attributes in Mediterranean forest stands. Eur. J. Remote Sens. 51, 795-807.

doi.org/10.1080/22797254.2018.1482733

Gollob, C., Ritter, T., Nothdurft, A., 2020. Forest Inventory with Long Range and High-Speed Personal Laser Scanning (PLS) and Simultaneous Localization and Mapping (SLAM) Technology. Remote Sens, 12:1509. doi.org/10.3390/rs12091509

Li, W. K., Guo,Q. H., Jakubowski, M. K., Kelly, M., 2012. A new method for segmentation individual trees from the LiDAR point cloud. Photogrammetric Engineering and Remote Sensing, 78(1):75-84.

doi.org/10.14358/PERS.78.1.75

Liang, X., Wang, Y., Jaakkola, A. , Kukko, A., Kaartinen, H., Hyyppa, J., Honkavaara, E., Liu, J., 2015. Forest data collection using terrestrial image-based point clouds from a handheld camera compared to terrestrial and personal laser scanning.IEEE Trans. Geosci. Remote Sens. 53: pp. 51175132. doi.org/10.1109/TGRS.2015.2417316

Liang, X., Kukkoa, A., Hyyppäa, J., Lehtomäkia, M., Pyöräläa, J., Yua, X., Kaartinena, H., Jaakkolaa, A., Wang, Y., 2018. In-situ measurements from mobile platforms: An emerging approach to address the old challenges associated with forest inventories ISPRS Journal of Photogrammetry and Remote Sensing 143: 97-107.

doi.org/10.1016/j.isprsjprs.2018.04.019
LIDAR360 Development Team, 2020. Commercial software of Green Valley international company.

https:/greenvalleyintl.com/software/lidar360/

Maas, H. G., Bienert, A., Scheller, S., Keane, E., 2008. Automatic forest inventory parameter determination fromterrestrial laser scanner data. Int. J. Remote Sens. 29: 1579-1593. doi.org/10.1080/01431160701736406

Mondino, G.P., Bernetti, G., 1998. I tipi forestali. Boschi e macchie di Toscana. Regione Toscana. Giunta Regionale. Edizioni Regione Toscana. Firenze.

Oveland, I., Hauglin, M., Giannetti, F., Kjørsvik, N.S., Gobakken, T., 2018.Comparing three different ground based laser scanning methods for tree stem detection. Remote Sens. 10: 538. doi.org/10.3390/rs10040538

Pignatti, S., 1979 - Dieci anni di cartografia floristica nell' Italia di Nordest. Inform. Bot. Ital. 10: 212-219.

R Development Core Team. 2021. R: A language and environment for statistical computing. Vienna: Austria. Software, Version 4.0.5. http://www.r-project.org/ (31 March 2021).

Ryding, J., Williams, E., Smith, M., Eichhorn, M., 2015. Assessing Handheld Mobile Laser Scanners for Forest Surveys. Remote Sensing. 7-1:1095. doi.org/10.3390/rs70101095

Shao, J., Zhangc, W., Melladob, N., Wange, N., Jina, S., Caia, S., Luof, L., Lejembleb, T., Yana , G., 2020. SLAM-aided forest plot mapping combining terrestrial and mobile laser scanning. ISPRS Journal of Photogrammetry and Remote Sensing 163: 214-230.

doi.org/10.1016/j.isprsjprs.2020.03.008

Tabacchi, G., Di Cosmo, L., Gasparini, P., Morelli, S., 2011. Stima del volume e della fitomassa delle principali specie forestali italiane. Equazioni di previsione, tavole del volume e tavole della fitomassa arborea ed epigea. Consiglio per la Ricerca e la sperimentazione di Agricoltura, Unità di Ricerca per il Monitoraggio e la Pianificazione Forestale Trento, 412 pp.

Tao, S. L., Wu, F. F., Guo, Q. H., Wang,Y. C., Li, W. K., Xue, B. L., Hu, X. Y., Li, P., Tian, D., Li, C., Yao, H., Li, Y. M., Xu, G. C.,Fang, J. Y., 2015. Segmentation tree crowns from terrestrial and mobile LiDAR data by exploring ecological theories. ISPRS Journal of Photogrammetry and Remote Sensing,110:66-76. doi.org/10.1016/j.isprsjprs.2015.10.007

ZEB HORIZON тм - GeoSLAM, 2020. Commercial laser scanner of GeoSlam company.

https://geoslam.com/solutions/zeb-horizon/ 